\title{
Self-Promoting Investments
}

\author{
Carolyn Pitchik* \\ Deptment of Economics \\ University of Toronto \\ pitchik@chass.utoronto.ca
}

April 21, 2006

\begin{abstract}
When human capital skills differ in their ability to attract offers from alternative employers, a potential inefficiency in human capital investment arises. If a worker's ability and investments are observed by the labour market only when the worker invests in self-promoting activities, then highability workers overinvest in self-promotion. No bond is posted in the contract that both attains efficient investment and minimizes the bond subject to individual rationality constraints and the zero profit condition. The contract is one in which the firm (i) offers to match outside offers strategically and (ii) guarantees a minimum wage. The model predicts that, under both the spot market contract and the efficient contract, wage declines with seniority even when conditioning on high ability. This prediction is consistent with the stylized fact regarding the decline of wages with seniority in academia. The model can also explain how the seniority wage premium may vary across disciplines, time, and schools.
\end{abstract}

Keywords: negative seniority wage premium, spot market contract, efficient contract, general human capital

JEL Classification: C7, C72, L1

*I thank Michelle Alexopolous, Arthur Hosios, Gueorgui Kambourov, Preston McAfee, Martin Osborne, and seminar participants at Queen's University, University of Toronto, Pennsylvania State University, Wilfrid Laurier University, the Canadian Economic Theory Conference, the Australian National University and Washington University for useful suggestions. I particularly thank Aloysius Siow for many fruitful discussions during the conception and earlier stages of this project. I gratefully acknowledge financial support from SSHRC. 


\section{Introduction}

While on the job, workers invest in general human capital skills to make themselves more valuable to their employers, and also more attractive to other firms. Skills differ in their potential for attracting the attention of employers, both internal ${ }^{1}$ and external. I call a skill "visible" if it has a strong potential for attracting the attention of external employers. Such employers who recognize a worker's high level of some visible skill may try to attract the worker by offering a higher wage. This activity gives workers in a spot market an incentive to over-invest in the selfpromoting visible skill. I investigate contracts that induce efficient investment in both visible and invisible skills. My general objective is to understand the employment relationship that develops under such circumstances.

Efficient investment may be induced by a contract in which a worker posts a "bond" that is forfeited if the worker is revealed not to have invested efficiently. No bond is needed in the efficient contract that I consider. The infrequent arrival of outside offers can be exploited by a firm in its design of this contract. Under the efficient contract, a firm assesses a worker who reveals an outside offer. The contract provides incentives for efficient investment by: (1) a promise to match an outside offer received by any worker who produces an efficient output; (2) a commitment not to match outside offers of a worker who produced an inefficient output; (3) a guarantee of a minimum base wage. An implication of (2) is that those who invest inefficiently generate only low outside offers.

A motivation for my model is the observation that in academia, professors often use outside offers to obtain a raise in salary from their employer. A rationalization of this practice is that it is costly for universities to observe the market value of a faculty member in the absence of an outside offer, so that, to minimize inspection costs, they inspect the value of an employee and increase the employee's salary significantly only when the employee reveals a credible outside offer.

\footnotetext{
${ }^{1}$ The more general the human capital skills, the higher the cost a firm incurs to discover the skills in which a worker has invested.
} 
I find that, under either the spot market contract or the efficient contract, the average wage of those who leave a firm is strictly higher than that of those who remain. This difference persists even when I condition on productivity. This fits the empirical findings of Ransom (1993) and Bratsberg et al. (2003) regarding the U.S. academic labour market. They find that the salaries of academics, unlike salaries in the non-academic labour force, decrease with seniority even when controlling for productivity. (Ransom uses cross section data and controls for quantity of publications, Bratsberg et al. use panel data and control for both quantity and quality of publications.) In a model in which visible skills are present, Lazear (1986a) and Harris and Holmstrom (1982) find analytically that the average wage of those who leave is higher than that of those who remain but that the differences disappear when conditioning on productivity. Thus, these models do not explain the empirical negative seniority wage premium in academia. Ransom (1993) suggests that high employee moving costs explain the difference between the market wage of an academic and the wage that an incumbent university needs to pay. His analytical findings remain when he conditions on productivity. His model predicts that the negative seniority wage premium (even when controlling for productivity) should exist in any industry (including that of academics and professional athletes who are free agents) for which the worker's human capital is mainly general (or at least industry-specific) and moving costs are positive (e.g., when jobs are isolated geographically). By contrast, my model makes no prediction for professional athletes (who are evaluated constantly and publicly) but does make predictions for academics (who are evaluated upon promotion and upon receiving outside offers).

I find that the negative seniority wage premium holds whenever

- Human capital is general (or, at least, industry- and not firm-specific).

- There are no trade secrets.

- Outside offers are scarce.

- The employee engages in multiple tasks, some of which are visible. 
- Employee output is costly to assess.

The first two assumptions are implicit. Trade secrets and firm-specific human capital skills are absent in my model. (If they were present, outside offers would be counterproductive for a firm). In academia, professors have little firm-specific human capital and few trade secrets so that the use of outside offers to generate internal pay raises is efficient.

This paper complements research aiming to understand the contracts and incentives that emerge when employees may invest in human capital that is valuable both to their current employer and to alternative employers. Carmichael (1983, 1988), Malcomson (1984), Waldman (1984, 1990), Milgrom and Oster (1987), Kahn and Huberman (1988), MacLeod and Malcomson (1988), Ricart i Costa (1988), Gibbons and Katz (1991), Bernhardt and Scoones (1993), Bernhardt (1995), Chang and Wang (1996) and Acemoglu and Pischke (1998) explore how employers manipulate rules of promotion and hiring when their knowledge about their employees is superior to that of alternative employers. Instead, this paper studies the case in which career concerns motivate workers to promote themselves directly to the market so that the knowledge of alternative employers about an incumbent employer's workers may be equal or superior to that of the incumbent firm. (The asymmetric information assumption that I employ is realistic when, for example, a firm has many branches ${ }^{2}$ or when workers are highly specialized ${ }^{3}$. A variant of the model with symmetric information is considered in Section 3.) In the career concerns literature ${ }^{4}$, a worker chooses how much costly investment to make in output that is used by the market to assess and reward talent in a future career. In this paper, a worker chooses how much time to allocate to a task that affects both output and the probability that the market assesses and rewards output in the future with no change in career choice. These implicit incentives

\footnotetext{
${ }^{2}$ If a firm is geographically separated from head office, local competitors may have a better idea of the branch manager's efforts and skills than does head office.

${ }^{3}$ If workers are highly specialized, a manager may not be able to evaluate the contribution of each specialist as well as other specialists in competing firms.

${ }^{4}$ See for example, Dwatripont, Jewitt and Tirole (1999).
} 
motivate the worker to over-allocate time to the visible task in the spot market. The presence of these implicit incentives may give rise to explicit contracts offered by the firm that mitigate against this inefficient allocation of time.

My model is related also to models of multi-tasking and influence activities (Milgrom and Roberts (1982) and Milgrom (1988), Holmstrom and Milgrom (1991)). The basic multi-tasking model in these papers ignores the effect on outside options of time allocation across tasks. I apply it in an environment in which time allocation across visible and invisible skills affects the generation of outside offers: the more time that a worker invests in the visible skill, the higher the probability that an outside offer is generated.

Since the returns to time allocated to the visible task are not realized unless an outside offer is received, the model shares features common to the hold-up literature ${ }^{5}$. In both the spot market contract and the efficient contract, the firm commits to a base wage that may be enhanced when an outside offer is received.

\section{The Model}

Firms live indefinitely. Short-lived risk-neutral workers work for two periods in a perfectly competitive industry (in which profits are zero) and maximize their expected present value of income and benefits. The proportion $\pi^{h}$ of the workers have high ability $h$, and the proportion $\pi^{l}=1-\pi^{h}$ have low ability $l$, where $l<h$. Ability affects production. In the academic labour market, ability indicates the quality of an academic's publications. The longer a $\theta$-ability academic spends on research, the higher the production of $\theta$-quality publications where $\theta \in\{h, l\}$.

Initially, the worker and firm (denoted the inside firm) sign a contract detailing the terms of the worker's employment. The details depend on whether short- or long-term contracts are feasible. After an agreement is made, the employee's ability is observed by the employee on the job at the beginning of the first period. Once ability is observed, the worker allocates one unit of time across visible and

\footnotetext{
${ }^{5}$ See, for example, Edlin and Riechelstein (1996).
} 
invisible activities. The visible activity affects productivity in the second period and visibility in the labour market. Output in the first period, denoted $Y_{0}$, is independent of a worker's type and allocation decision. The values of $t$ and $\theta$ in the first period are not observed by employers.

The second period output of a worker of type $\theta \in\{h, l\}$, who, in the first period, allocates time $t \in[0,1]$ on $V$ is $y(t, \theta)=Y(V(t, \theta), I(1-t, \theta))$ where $V(t, \theta)$ and $I(1-t, \theta)$ are the visible and invisible activity levels. At the beginning of the second period, the first period allocation $t$ of a worker of type $\theta$ results, with probability $p(t, \theta)$, in the revelation of the worker's second period output $y(t, \theta)$ to an outside firm, in which case this firm makes an offer of a second period wage. An academic's publication record attracts the scrutiny of the academic's publications and teaching through the process of a job offer. The quality of the outside institution can be interpreted as an indication of the output of the worker.

I assume that there is an idiosyncratic component to the match between a firm and a worker (which generates mobility). The value of a worker to each firm is the output $y(t, \theta)$. A worker values not only wages but also benefits (e.g. pension schemes, positive externalities generated by colleagues, lifestyle opportunities afforded by a particular location). I assume that the firm can vary the wage but not the benefit. Benefits differ across firms so that a worker's valuation of a given wage offer depends on the firm that makes the offer. As it is the difference in benefits that matters, I assume that the value to the worker of the benefits of the inside firm is zero while that of the benefits of an outside firm is $x$, which is distributed according to $H$ on $[-b, b]$ with a mean of zero. Once an offer has been received but before the worker knows the value of $x$, the worker decides whether or not to reveal this information credibly to the inside firm. The worker observes $x$ when negotiations take place over offers and counteroffers.

I assume that output $y(t, \theta)$ is increasing in $\theta(y(t, h)>y(t, l)$ for all $t)$, concave in $t$, and single peaked in $t$ for $t \in(0,1)$. In addition, I assume that a high-ability worker has a comparative advantage in the visible activity: (i) a worker's efficient 


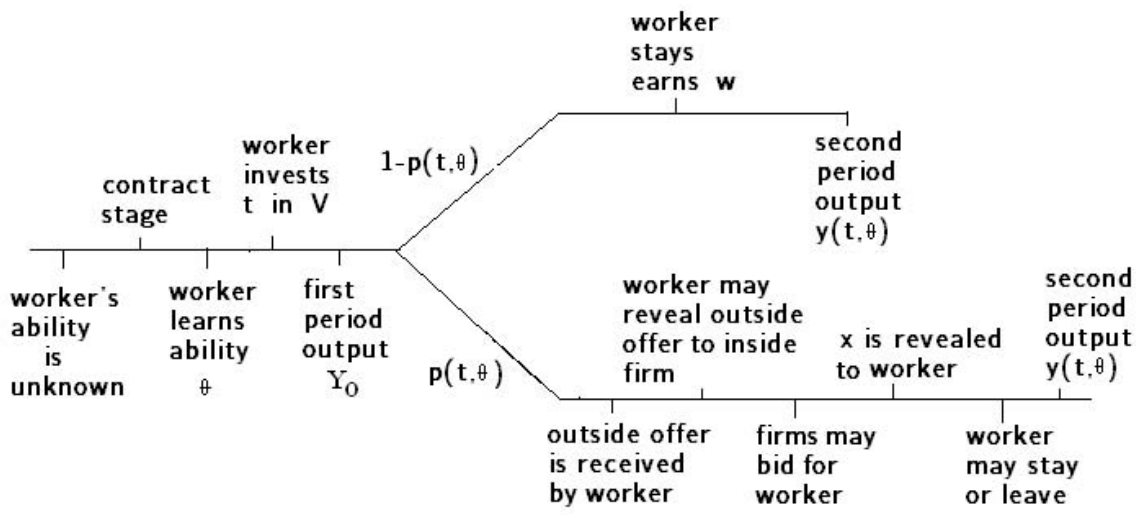

Figure 2.1: Timeline of Events

allocation $^{6}$ in the visible activity rises with ability and (ii) the efficient output of a high-ability worker is unattainable by a low-ability worker. Thus, ability confers real differences in productive capabilities among workers. Even when allocating all available time to research, a low-ability academic is unable to produce the high-quality research output of a high-ability academic.

Visible acitivities $V$ are valued by the firm and also enhance a worker's chance of being seen to be valuable. I assume that, for any allocation of time, a more able worker is at least as likely to be revealed to an outside firm as a less able worker; that is, $p$ is increasing in $\theta$ for all $t \in(0,1)$ and that $p(0, \theta)=0$ for $\theta \in\{h, l\})$. (This makes sense in the academic labour market as high-quality publications attract more notice than low-quality publications.) I assume that $p$ is increasing and concave in $t$. The model is illustrated in Figure 2.1.

\footnotetext{
${ }^{6}$ The efficient allocation conditional on an efficient match maximizes output $y(t, \theta)$. The unconditional efficient allocation maximizes the expected surplus $y(t, \theta)+p(t, \theta) E \max \{0, x\}$.
} 
My aim is to analyze short-term spot market contracts and long-term efficient contracts. By assumption, a firm that reneges on a long-term contract is believed to operate under a spot market (short-term) contract in the future. I consider the efficient investment, the spot market outcome, and then the efficient contract.

\subsection{The Efficient Allocation of Time}

Since wages transfer wealth from firms to workers, if the current match between worker and firm cannot be improved upon, the efficient allocation of time maximizes output $y(t, \theta)$. Let subscript $t$ denote the variable of partial differentiation. The conditional efficient investment $\kappa(\theta)$ of a worker of ability $\theta$ satisfies

$$
y_{t}(\kappa(\theta), \theta)=0 .
$$

The unconditional efficient investment of time takes into account that investment affects the probability of obtaining a better match. That is, the unconditional efficient investment $T(\theta)$ of a worker of type $\theta$ maximizes the expected surplus

$$
(1-p(t, \theta)) y(t, \theta)+p(t, \theta)(y(t, \theta)+\exp \max \{0, x\})
$$

If exp $\max \{0, x\}$ satisfies $y_{t}(1, \theta)+p_{t}(1, \theta) \exp \max \{0, x\}<0$, then $T(\theta)$ satisfies

$$
y_{t}(T(\theta), \theta)+p_{t}(T(\theta), \theta) \exp \max \{0, x\}=0
$$

I briefly discuss the case that $T(\theta)=1$ in Section 3 .

By assumption, a high-ability worker has a comparative advantage in the visible activity so that the efficient investments (both $\kappa(\theta)$ and $T(\theta)$ ) increase in ability. ${ }^{7}$ That the efficient (both conditional and unconditional) output increases in ability follows from the assumption that both $y(t, \theta)$ and $p(t, \theta)$ increase in $\theta$. The result below compares the two efficient investments.

\footnotetext{
${ }^{7}$ If the derivatives $y_{t}$ and $p_{t}$ increase in $\theta$ for $t \in[0,1]$, then this implies a single crossing property that is sufficient to imply both that the effiicent investment increases in ability and that a low ability worker is unable to produce the constrained efficient output of a high ability worker. See Proposition A.1 in the Appendix.
} 
Proposition 2.1. $T(\theta)>\kappa(\theta)$ for $\theta \in\{l, h\}$. If $y_{t}$ or $p_{t}$ shifts up, then $T(\theta)$ and $\kappa(\theta)$ both increase.

Proof. This follows from concavity of $y$ and $p$ and monotonicity of $p$ in $t$.

This makes sense. Whenever the effectiveness of time spent on the visible activity increases, the efficient level of the visible activity increases. Note also that the presence of $\exp \max \{0, x\}$ distorts the unconditional efficient investment away from the conditional efficient investment. I assume that this distortion is small enough that, a low-ability worker is unable to produce the unconditional efficient output of a high-ability worker.

\subsection{The Spot Market Outcome}

I assume that long-term contracts are infeasible in the spot market for workers. Firms earn zero profits and may enter and exit costlessly.

Since workers in the first period are identical, each worker earns first-period output $Y_{0}$ in the first period in a spot market. Assume that the initial contract specifies that a worker earns a base wage of $w$ in the second period if no outside offers have been revealed. (Later I discuss the equilibrium spot wage.)

If a worker (of type $\theta$ who invests $t$ ) receives an outside offer and reveals it to the inside firm, a bidding process begins. This bidding process is modelled as an ascending bid oral auction with two bidders whose common valuation equals the worker's output $y(t, \theta)$. In equilibrium, each firm bids up to the worker's output so that the worker's expected salary plus benefits is $y(t, \theta)+\exp \max \{0, x\}$. If the worker does not reveal an outside offer then the worker earns $w$ in salary and expected benefits. A worker reveals outside offers only when $y(t, \theta) \geq w-$ $\exp \max \{0, x\}$ and so outside firms make offers only to workers whose output is at least as high as $w-\exp \max \{0, x\}$. Thus, if $y(t, \theta) \geq w-\exp \max \{0, x\}$ then, with probability $p(t, \theta)$, there is an outside bidder and the worker obtains $y(t, \theta)+\exp \max \{0, x\}$. The possible consequences of a worker's decision to choose $t$ such that $y(t, \theta) \geq w-E \max \{0, x\}$ are depicted in Figure 2.2. 


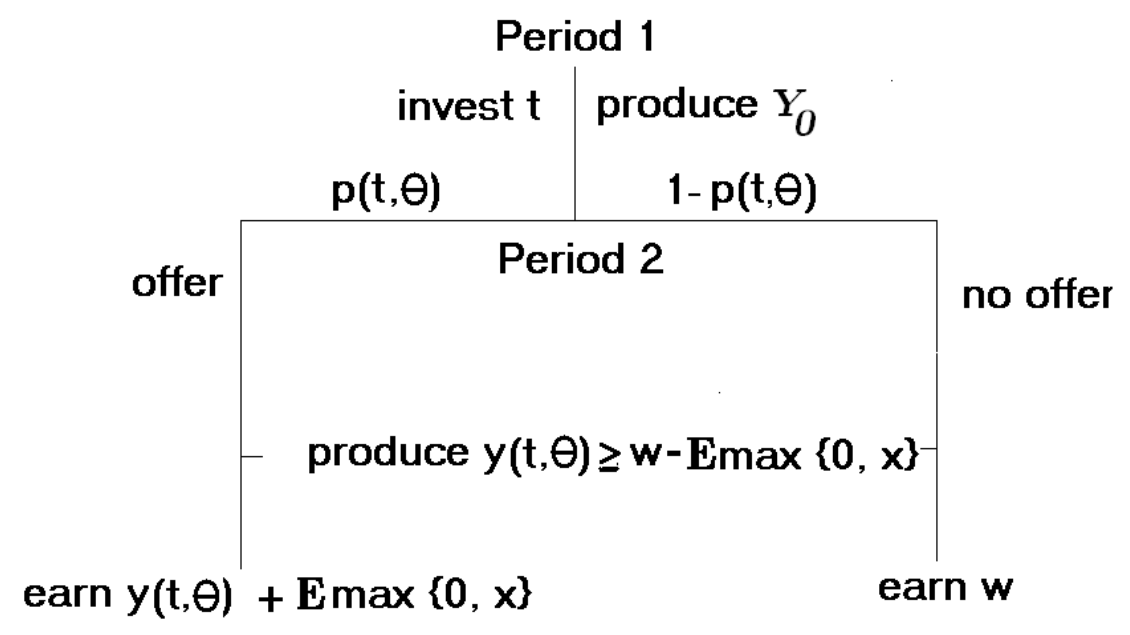

Figure 2.2: Consequences of a Worker's Decision if $y(t, \theta) \geq w-\exp \max \{0, x\}$

\subsubsection{Spot Market Investment in Visible Skills}

Given the current base wage $w$ and expected non-wage benefits $\exp \max \{0, x\}$, a worker of type $\theta$ maximizes expected income by choosing an investment $t \in[0,1]$ to maximize $G(t, \theta, w-\exp \max \{0, x\})$

$=\left\{\begin{array}{ll}w+p(t, \theta)[y(t, \theta)-(w-\exp \max \{0, x\})] & \text { if } y(t, \theta) \geq w-\exp \max \{0, x\} \\ w & \text { if } y(t, \theta)<w-\exp \max \{0, x\}\end{array}\right.$.

Denote the maximizer by $\tau^{\theta}(w-\exp \max \{0, x\})$. If $w-\exp \max \{0, x\}>y(\kappa(\theta), \theta)$ then the worker's highest expected income is $w$. The worker reveals no offers in this case and so is indifferent among all allocations. So as not to artificially bias the results away from the efficient allocation and to maintain continuity, I assume that the worker invests the conditional efficient amount $\kappa(\theta)$ in this case. The next result states that the worker over-invests in $V$ in the spot market when $y(\kappa(\theta), \theta)>w-\exp \max \{0, x\}$. Proofs omitted from the text are in the Appendix. 


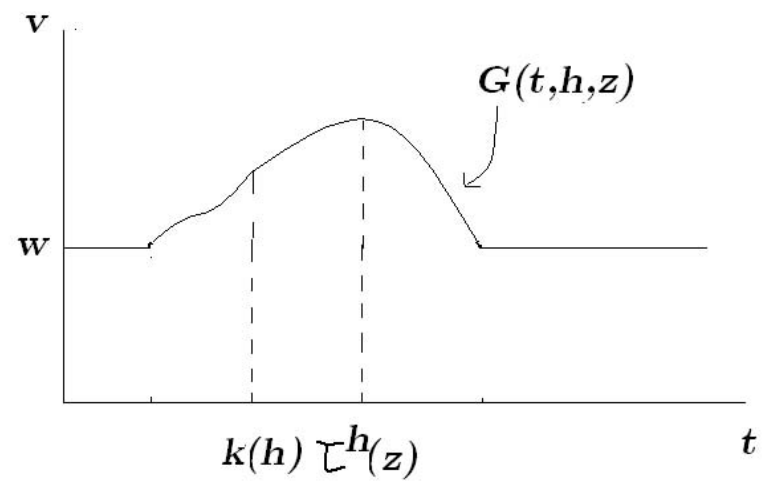

Figure 2.3: Graph of $G$ if $y(\kappa(h), h)>z=w-\exp \max \{0, x\}$

Proposition 2.2. If $y(\kappa(\theta), \theta)>w-\exp \max \{0, x\}$ then (1) first order-conditions are sufficient to characterize $\tau^{\theta}(w-\exp \max \{0, x\})=\arg \max _{t} G$ and (2) $\tau^{\theta}(w-$ $\exp \max \{0, x\})$ exceeds the conditional efficient level of investment $\kappa(\theta)$.

The intuition for over-investment in the visible activity is as follows. A worker does not receive any benefit from investment unless an outside offer is generated. When $w$ - exp $\max \{0, x\}$ is low enough, a worker therefore over-invests in the activity that increases the chance that the worker receives such an offer. A possible graph of $G$ for $\theta=h, y(\kappa(h), h)>w-\exp \max \{0, x\}$ is given in Figure 2.3.

If we let $z=w-\exp \max \{0, x\}$ the optimal allocation $\tau^{\theta}(z)$ is characterized using first order conditions as indicated in Proposition 2.2.

- $\tau^{\theta}(z)=1$ if

$$
z<y(1, \theta)+\frac{p(1, \theta) y_{t}(1, \theta)}{p_{t}(1, \theta)}
$$

- $\tau^{\theta}(z)$ satisfies

$$
p_{t}(t, \theta)[y(t, \theta)-z]+p(t, \theta) y_{t}(t, \theta)=0 \text { for } t \in(\kappa(\theta), 1)
$$


if

$$
y(1, \theta)+\frac{p(1, \theta) y_{t}(1, \theta)}{p_{t}(1, \theta)}<z<y(\kappa(\theta), \theta)
$$

- $\tau^{\theta}(z)=\kappa(\theta)$ if $z>y(\kappa(\theta), \theta)$.

Proposition 2.3. The spot market investment decreases for $z$ in the range (2.4).

Intuitively, the value of an offer decreases as the base wage increases, so that the benefit of another unit of time invested decreases.

\subsubsection{Spot Market Base Wage}

Long-term contracts are infeasible and firms expect to earn zero profits in the spot market. In the event that a worker reveals an outside offer to the inside firm, competition for the worker bids up the worker's price to the point at which the firm makes zero profits whether the worker stays or not. Since the firm earns zero profit on those workers who receive an offer but stay with the firm and the firm earns zero profits over all workers, the firm must also expect to earn zero profit on those workers who do not reveal an offer and so stay and earn the base wage. That is, competition in the spot market forces the base wage to be equal to the expected output of those who receive it. Suppose for example that the firm makes positive profit on average $e^{8}$ by paying a current base wage that is less than the average output of those who receive it. In this case, one of two possibilities can occur. Another firm can offer a more attractive package (from the worker's point of view) that is also profitable (from the firm's point of view) by offering a higher base wage. This higher base wage, coupled with the spot market counteroffers, is more attractive than the current base wage and so would attract all the base wage earners away from the firm that offers the current lower base wage. Alternatively, if there are no other feasible profitable contracts that attract workers away from a firm that offers the current low base wage, then entry occurs. Entry affects the

\footnotetext{
${ }^{8}$ The case in which the firm makes negative profits on those who receive the base wage cannot be sustained as the firm would then make negative profits on average.
} 
probability of receiving an offer and the expected output of workers who receive the base wage. Adjustments take place until the base wage equals the expected output of those workers who earn the base wage so that the firm earns zero profits.

As a consequence, the equilibrium spot market base wage is a fixed point of an appropriately defined function. An application of the envelope theorem implies that a worker's expected spot market wage rises with the base wage. In addition, as the base wage increases, the optimal investment decreases toward the efficient investment and therefore output increases. Thus, if there are multiple fixed points, it makes sense for the spot market equilibrium wage to be the maximum of all such fixed points. It remains to argue that there exists a fixed point.

Proposition 2.4. The spot market equilibrium base wage exists. At this wage, the high-ability worker receives offers with positive probability and the spot market equilibrium investment of the high-ability worker is greater than the unconditional efficient investment $T(h)$ of such a worker.

The assumption that knowledgeable outside firms are scarce is reasonable when information is costly and workers have to invest in self-promoting activities to attract outside offers. As the cost of information decreases to zero, entry occurs so that the probability that a worker receives a counteroffer increases. As the probability of receiving a counteroffer increases to one for all investment levels, the spot market investment decreases to the efficient level.

Since the spot market wage $w_{s}$ equals the expected output of those workers who receive it and since those who don't receive the base wage receive a wage equal to output, the expected wage of a random worker in the spot market equals

$$
\pi^{l} y\left(\tau^{l}\left(z_{s}\right), l\right)+\pi^{h} y\left(\tau^{h}\left(z_{s}\right), h\right)
$$

where $z_{s}=w_{s}-\exp \max \{0, x\}$.

Theorem 2.5. Under the spot market contract, the average wage of those who leave a firm is strictly higher than the average wage of those who remain. This difference persists even when we condition on high ability. 


\subsection{The Efficient Contract}

Recall that the unconditional efficient investment $T(\theta)$ solves (2.2). It is easy to devise a long-term contract that elicits this efficient investment, $T(\theta)$, on the part of a worker if the worker is able to post a bond in the first period (which is forfeited if the worker's investment is not efficient). If there is no bound to the bond that workers can pay then many contracts elicit efficient investment but not all such contracts are satisfactory. Two reasons are as follows.

1. Workers may not be matched efficiently to the inside and outside firms.

2. The bond that workers pay in the first period to sustain the contract may be substantial. If workers have limited access to capital markets, the contract may not be feasible.

I find the minimum bond associated with a contract that achieves efficient investment and matching. The class of contracts that I consider stipulates payment to the worker as a function of the information that the firm has about the worker. The firm either knows $y(t, \theta)$ (because the worker has received an offer and revealed it to the firm) or doesn't know $y(t, \theta)$ (because the worker has not received an offer or has received an offer but did not reveal it to the firm). A contract needs to stipulate what the worker receives in each case. The contracts are best understood if one views the inside firm as selling the services of the worker to an outside firm when it is efficient to do so.

Consider the set of contracts $\Omega=\left\{\left(w, C^{h}, C^{l}\right) \in \Re^{3}: w \geq 0\right\}$ where $\Re$ is the set of real numbers and a contract is interpreted as follows. The employer offers to pay (1) $w$ to all workers who either do not reveal an offer or reveal an offer and production level different from $y(T(\theta), \theta)$ for $\theta \in\{h, l\}$, and $(2) w+C^{\theta}$ to all workers who reveal an offer and production level $y(T(\theta), \theta)$ for $\theta \in\{h, l\}$. Note that, by the terms of any contract in $\Omega$, a worker can earn at least $w$ by never revealing an outside offer, so that consistency requires $w+C^{\theta} \geq w$ for $\theta \in\{h, l\}$. Thus, the relevant set of contracts is $\Omega^{+}=\left\{\left(w, C^{h}, C^{l}\right) \in \Re^{3}: w, C^{h}, C^{l} \geq 0\right\}$. 
Each contract in $\Omega^{+}$is associated with a bond (posted by a worker in the first period) that equals the expected loss of the firm in the second period (the payment to the worker less the expected revenue from the worker's services).

Let us interpret $w$ to be a base wage; $C^{\theta}$, a counteroffer (over and above the base wage) for $\theta \in\{h, l\}$; and $y(T(\theta), \theta)$ for $\theta \in\{h, l\}$, a target output level whose revelation triggers a counter offer for a worker. We look for the contract that minimizes the bond payment among incentive compatible, individually rational, efficient equilibrium contracts in $\Omega^{+}$. I first discuss the constraints.

In order that a contract in $\Omega^{+}$elicit the efficient outcome, four sets of individual rationality constraints must be satisfied. (1) Workers must be matched efficiently when possible and a worker of type $\theta$ must want to invest in the efficient level $T(\theta)$. (2) Workers who invest efficiently must prefer to accept the payments from the firm rather than negotiate separately with a raider. (3) It must not be possible for a firm to renege on any detail of the contract and make a profit. (4) Since firms are profit-maximizers, there must not be a feasible profitable contract that attracts workers away from firms that offer the efficient contract.

I now determine the constraints that the first two conditions impose on a contract in $\Omega^{+}$. The first constraint requires that workers choose the efficient level of investment in $V$. A worker of any type who produces a target output $y(T(\theta), \theta)$ for some $\theta \in\{h, l\}$ earns at least $w$ under a contract in $\Omega^{+}$since each counteroffer $C^{\theta} \geq 0$, for $\theta \in\{h, l\}$. A worker whose output differs from each target output makes at most $w$ since a raider need not offer more than $w$ to a worker who receives no counteroffers. Thus, a worker prefers to produce a target output when facing a contract in $\Omega^{+}$. Can a worker produce a target output by investing inefficiently? Since $p$ is increasing in the investment, a worker of type $\theta$ prefers to produce $y(T(\theta), \theta)$ by investing $T(\theta)$ rather than by investing $t<T(\theta)$ (by Proposition 2.1 and by concavity only $t<T(\theta)$ is feasible). Does a worker of one type want to pretend to be another type? A worker of type $l$ is incapable of producing $y(T(h), h)$. However, a worker of type $h$ can pretend to be of type $l$. In order that a worker of type $h$ prefer to produce $y(T(h), h)$ rather than $y(T(l), l)$ it 
is required that $p(T(h), h) C^{h} \geq p(t, h) C^{l}$ for any $t$ such that $y(t, h)=y(T(l), l)$. Let $\widetilde{T}(h)$ denote the largest ${ }^{9}$ such investment level.

The first constraint requires also that workers are matched efficiently to firms whenever a worker's production is revealed. In the case that a worker leaves, the inside firm recovers payment equal to the worker's output from the outside firm. Thus, whether the worker leaves or stays, the inside firm receives a benefit equal to a worker's output. In this case, it is optimal for a firm to sell the services of a revealed worker to a rival firm only when $x>0$.

The second constraint requires that workers have no incentive to negotiate separately with the outside firm when the opportunity arises. For $\theta \in\{h, l\}$, let $p^{\theta^{*}}$ denote $p(T(\theta), \theta)$, the efficient probability that an offer is received, and let $y^{\theta^{*}}$ denote $y(T(\theta), \theta)$, the efficient output. Under a contract in $\Omega^{+}$, once a worker reveals $y^{\theta^{*}}$, the outside and inside firms each value the worker at $y^{\theta^{*}}$ and a worker is paid $w+C^{\theta}$. However, the worker can always earn $w$ by not revealing an outside offer. Consequently, the constraint requires that $w+C^{\theta} \geq \max \left\{w, y^{\theta^{*}}\right\}$.

I now consider the variation in the implicit bond across contracts in $\Omega^{+}$that satisfy the first two individual rationality constraints. The inside firm pays the worker at least $w$ whether or not the worker receives an offer. When the worker receives and reveals an offer, the firm pays $C^{\theta}$ if the output produced is $y^{\theta^{*}}$. The inside firm receives the benefit of the worker's productivity directly if the worker stays and indirectly if the worker leaves. If we recall that $y(\widetilde{T}(h), h)=y(T(l), l)$, then the bond

$$
\begin{aligned}
B\left(w, C^{h}, C^{l}\right) & =\sum_{\theta \in\{h, l\}} \pi^{\theta}\left\{w-y^{\theta^{*}}+p^{\theta^{*}} C^{\theta}\right\} \text { where } \\
\left(w, C^{h}, C^{l}\right) & \in \Omega^{+}, \\
w+C^{\theta} & \geq \max \left\{w, y^{\theta^{*}}\right\} \text { for } \theta \in\{h, l\} \text { and } \\
p^{h^{*}} C^{h} & \geq p(\widetilde{T}(h), h) C^{l} .
\end{aligned}
$$

\footnotetext{
${ }^{9}$ Ceteris paribus, a worker prefers the higher probability of an offer (which increases in $t$ ).
} 
Denote by $C^{l^{*}}(w)$ the minimum feasible value of $C^{l}$ given $w$ so that

$$
C^{l^{*}}(w)= \begin{cases}y^{l^{*}}-w & \text { if } 0 \leq w \leq y^{l^{*}} \\ 0 & \text { if } y^{l^{*}} \leq w\end{cases}
$$

which is piecewise linear, continuous, decreasing and convex in $w$.

Denote by $C^{h^{*}}(w)$, the minimum feasible value of $C^{h}$ given $w$ and $C^{l^{*}}$ so that

$$
C^{h^{*}}(w)= \begin{cases}\frac{p(\widetilde{T}(h), h)\left(y^{l^{*}}-w\right)}{p^{h^{*}}} & \text { if } 0 \leq w \leq \bar{y} \\ y^{h^{*}}-w & \text { if } \bar{y} \leq w \leq y^{h^{*}} \\ 0 & \text { if } y^{h^{*}} \leq w\end{cases}
$$

where $\bar{y} \in\left(0, y^{l}\right)$ solves

$$
\frac{p(\widetilde{T}(h), h)\left(y^{l^{*}}-\bar{y}\right)}{p^{h^{*}}}=y^{h^{*}}-\bar{y} \text { if } \frac{y^{l^{*}}}{y^{h^{*}}} \geq \frac{p^{h^{*}}}{p(\widetilde{T}(h), h)}
$$

and $\bar{y}=0$ if not. The minimum feasible value of $C^{h}\left(C^{h^{*}}(w)\right)$ is piecewise linear, continuous, decreasing and convex in $w$.

Proposition 2.6. Given any fixed base wage $w$, the bond associated with an efficient contract $\left(w, C^{h}, C^{l}\right) \in \Omega^{+}$that satisfies the first two individual rationality constraints decreases as $C^{h}$ and $C^{l}$ decrease until $C^{l}=C^{l^{*}}(w)$ and $C^{h}=C^{h^{*}}(w)$.

Proof. The bond is linear, separable and increasing in the base wage and the counteroffers. Therefore, conditional on a base wage, the bond decreases as $C^{l}$ and $C^{h}$ decrease until $C^{l}=C^{l^{*}}(w)$ and $C^{h}=C^{h^{*}}(w)$.

Thus, for any given base wage $w$, the minimum bond must consist of counteroffers that are at the boundary levels $C^{\theta^{*}}(w)$ for $\theta \in\{l, h\}$ imposed by the first two individual rationality constraints. Let $\widetilde{p}=p(\widetilde{T}(h), h)$ and let $B^{*}(w)=$ $B\left(w, C^{h^{*}}(w), C^{l^{*}}(w)\right.$ ) (where $B$ is defined in (2.6)) be the value of the bond for a given base wage and its minimum counteroffers. In the efficient contract that minimizes the bond subject to all four individual rationality constraints, the base wage and counteroffers are uniquely determined in the next theorem. 
Theorem 2.7. In the efficient contract $\left(w, C^{h}, C^{l}\right) \in \Omega$ that minimizes the bond subject to the four individual rationality constraints, the base wage equals

$$
w_{e}=\frac{\pi^{l} y^{l^{*}}+\pi^{h} y^{h^{*}}\left[1-p^{h^{*}}\right]}{\pi^{l}+\pi^{h}\left[1-p^{h^{*}}\right]} \in\left(y^{l^{*}}, y^{h^{*}}\right),
$$

the bond $B^{*}\left(w_{e}\right)=0$, and the counteroffers are

$$
C^{h}=C^{h^{*}}\left(w_{e}\right)=y^{h^{*}}-w_{e} \text {, and } C^{l}=C^{l^{*}}\left(w_{e}\right)=0 .
$$

Note that, in essence, under the efficient contract, the firm pays the low-skilled worker a severance package $w-y^{l^{*}}$ whenever the low-skilled worker receives an offer from an outside firm that provides the worker with a superior match.

In the proof of Theorem 2.7 I argue that reputation plays a role in providing incentivies for the firm to make good its threat to reward only workers who have revealed efficiently. Let's consider the following example from academia. Suppose that all but one individual at a middle-ranked school is investing efficiently in research and teaching. One of its professors has received an offer that indicates more than the efficient number of middle-brow research publications at the cost of a notable decrease in teaching effectiveness relative to some norm. The school has two options, both of which result in zero profits. One option is not to respond to the offer as promised. Though not modelled as such, it may do so in the hopes of opening up a slot to someone who invests efficiently. Another option is to break its commitment and offer a bonus to the inefficient invester. It then takes the risk that all other such professors at the school then over-invest in low- to middle-brow research and under-invest in teaching in order to increase their chances of receiving a bonus. As argued in the Appendix, expected wages are higher under the efficient contract than under the spot market contract and so workers would eventually leave the school. A mid-ranked school does not have unlimited capacity to gain from more and more middle-brow research at the expense of teaching. Middlebrow research alone is not as highly valued at the school as a balance between middle-brow research and decent teaching. 
Below, as in the spot market contract, I show that there is a negative seniority wage premium for workers in the efficient contract. Intuitively, high-ability workers who leave the firm earn a high wage $y^{h^{*}}$ while high-ability workers who stay earn either $y^{h^{*}}$ or the base wage $w_{e}$. The wage of low-ability workers is constant at $w_{e}{ }^{10}$ Thus, the average wage of a leaver must be greater than that of a stayer.

Theorem 2.8. Under the bond-minimizing efficient contract, the average wage of those who leave a firm is strictly higher than the average wage of those who remain. This difference persists even when we condition on high ability.

The bond minimizing efficient contract (that satisfies the four individual rationality constraints) shares the following properties with the spot market contract.

(i) The base wage equals the expected output of those who receive it.

(ii) High-ability workers invest more in the visible activity.

(iii) High-ability workers are more likely to leave the firm.

(iv) The average earnings of those who leave the firm are higher than those of those who stay. This remains true when one conditions on high ability.

In addition, the bond minimizing efficient contract also satisfies.

(v) Only high-ability workers receive an increase in wage.

(vi) Low-ability workers who are revealed and leave are essentially paid a severance pay of $w_{e}-y^{l^{*}}$ to leave by the inside firm.

One incentive is provided by the threat of the incumbent firm to pay no more than $w_{e}$ to any worker who is revealed to have invested inefficiently. The implication of the incumbent firm's threat in this context is that a sole outside firm need not offer more than $w_{e}$ to such a worker. The incumbent firm exploits the scarcity of knowledgeable outside firms in the efficient contract. The assumption that knowledgeable outside firms are scarce is reasonable when information is costly and workers have to invest in self-promotion to attract outside offers.

\footnotetext{
${ }^{10}$ If one interprets $w$ as a salary (equal to average output) and $y^{h^{*}}$ as a piece-rate value of output (at a piece rate of 1 ) then the average output of those who receive a salary is less than that of those who receive the piece rate, as in Lazear (1986b).
} 
Another incentive in the contract is provided by the promise of the firm to match outside offers of those who make efficient investments. The promise of matching offers acts somewhat like a bonus in that it provides incentives for workers to invest efficiently. Note that the ability to commit is necessary for the contract to work. In the context of a game with a long-lived firm and shortlived workers who arrive periodically over an infinite horizon, commitment can be enforced by reputation as argued in the proof of Theorem 2.7. In the spot market case, it is profitable for the incumbent firm to match outside offers of inefficient workers since there is no reputation to lose by doing so.

If severance is not part of the contract, the low-ability worker chooses not to reveal any outside offer and remains with the firm so that the firm loses $w-y^{l^{*}}$ on each such worker. If severance pay is part of the contract, the firm is indifferent between the low-ability worker staying or leaving as the firm loses $w-y^{l^{*}}$ in either case. The firm has no positive incentive to offer severance pay but severance pay provides incentives for the low-ability worker to switch firms when it is efficient to do so. Thus, as in the hold-up literature (e.g. Edlin and Reichelstein, 1996) severance payments that are imposed by law and contingent on outside offers may be used to implement the efficient contract.

\section{Model Variations}

If, with probability $p(t, \theta)$ a worker's output is revealed simultaneously to both the inside and outside firms, an outside firm makes an offer even if $y(t, \theta)<z$ because the offer is automatically revealed to the inside firm. However, as in the basic model, workers who leave earn more on average than those who stay in both the spot market ${ }^{11}$ contract and the efficient contract.

If $\exp \max \{0, x\}$ is so large that $T(h)=1$ and $p(1, h)=1$, then the spot market contract is efficient and all high-skilled workers receive job offers so that

\footnotetext{
${ }^{11}$ The essential modification to the proof of Proposition 2.4 in the Appendix is that choosing $t=0$ takes the place of choosing not to reveal an offer. So, when $z=y(\kappa(\theta), \theta)$, the worker is indifferent between investing $t=0$ and investing $t=\kappa(\theta)$.
} 
the negative seniority wage premium disappears if one conditions on ability.

\section{Conclusion}

The model explains how a rational firm may respond strategically to outside offers in the presence of self-promoting activities. A rational employee seeks scarce outside offers that may result in an increase in salary. Firms exploit the scarcity of outside offers to induce employees to make the efficient investment. I conclude by offering more details of an application of the results to academia.

University administrators usually know less about a professor's productivity than do a professor's peers. ${ }^{12}$ Even if a department is informed of a professor's productivity, it may not be prudent for the university administration to rely on a department's internal evaluation. Frequently, professors at other universities have a more accurate perception of an individual's performance relative to that of the professor's university administration. Thus, the polar assumption of no insider informational advantage in the basic model is reasonable.

Academic research corresponds to the self-promoting investment in the model. Research increases both the productivity and visibility of the professor. Teaching corresponds to the non-visible activity of the model. ${ }^{13}$ Research is what entices a university to consider looking more closely at an individual. An offer from a school is a signal of a researcher's output. Even research which does not push the frontiers of knowledge might still give some indication of teaching ability. Most schools are interested somewhat in research and teaching. However, there is a limit to how much a low-ranked or middle-ranked school is willing to reward another medium-quality publication that is accompanied by a noticeable decrease in teaching effectiveness. The schools at the very top may be interested only in researchers whose efficient allocation of time is to spend all on high-quality research. An offer from a high-quality research insitituion is a signal of high-

\footnotetext{
${ }^{12}$ The problems that academic employers face are discussed more broadly in Siow (1998).

${ }^{13}$ University administration positions like Dean or Chair are scarce and so should be treated separately. Depending on the position, administration duties can be either visible or invisible.
} 
quality publications. An offer from a middle-quality research oriented school is a signal of reasonable quality publications and reasonable teaching. In my model, I assume that the signal of an offer is perfect. The main results of the model are robust to adding noise to the signal.

Due to the lack of information about how to evaluate the productivity of their professors, universities pay professors relatively uniform salaries within a discipline with the exception of those who receive an outside offer. Professors in some disciplines spend a lot of effort trying to generate outside offers. When a professor receives an outside offer that indicates efficient investment, the university begins to renegotiate the professor's salary. Whether the raider succeeds in attracting the professor or not, the professor ends up with a higher salary.

Not all academic offers need result in a counter-offer. Though there are only two levels of ability in the paper, I offer an explanation of this when there are three levels: high, medium and low. A middle-ranked research university may respond to an offer received by a top-ranked university as such an offer indicates the highest-quality of research and it could be that the efficient allocation of time to teaching is zero in this case. It may also respond to an offer received by a middle-ranked university as such an offer indicates mid-quality research and teaching. However, it may not respond to an offer from a low-ranked university as such an offer might indicate too much medium- or low-quality research relative to the teaching standard at a mid-ranked school. In other words, the counter-offer comes about as a result of accepted standards of teaching and research.

The process of raising salaries on the evidence of an outside offer can explain the empirical finding of a negative seniority wage premium in the U.S. academic labour. Ransom (1993), Hallock (1994), Moore et al. (1994) find that the wages of professors decrease with seniority in a university. Ransom obtains this empirical result using OLS on cross section data ${ }^{14}$ when controlling for experience and quantity of publications. Bratsberg et al. (2003) obtain this empirical result using

\footnotetext{
${ }^{14} \mathrm{He}$ uses cross section data on a large sample of universities from 1973. He also considers data from the University of Arizona for the years 1972, 77 and 82.
} 
OLS and Topel's two stage estimator on panel data ${ }^{15}$ when controlling for years of experience as well as publication quantity and quality ${ }^{16}$. This finding cannot be explained by an appeal to the ability of more productive workers to attract offers as it persists when the empirical studies control for productivity. This empirical finding in academia contrasts with the positive seniority wage premium found in the general working population (e.g. Altonji and Shakotko, 1987, Topel, 1991).

Ransom (1993) attributes the negative seniority wage premium in academia to monopsonistic salary discrimination. In his view, universities offer lower than market wages to those that remain in their employ to exploit the existence of positive moving costs. Only those employees with high moving costs remain. As time goes on, professors with high seniority will have higher average moving costs. In Ransom's model, the university knows the productivity, moving costs, and outside opportunities of each of its professors. The university pays each of its individual professors different wages. Professors face an outside market wage but may choose to stay and accept a lower wage due to the high cost of moving. In contrast, in my model, professors of a given productivity and seniority may receive differential salaries due to the random receipt of outside offers. Ransom's analytic model predicts that the negative seniority wage premium should exist in any industry for which the worker's human capital is mainly general (or, at least, industry-specific rather than firm-specific) and the moving costs are positive. His model predicts that the salaries of free agents in baseball and basketball and the salaries of non-unionized high school teachers should display the negative seniority

\footnotetext{
${ }^{15}$ They use longitudinal data to examine the salary of economics faculty at five public midranked universities in the Midwest U.S. from 1975 through 1995.

${ }^{16}$ Moore et al. (1998) use OLS on cross-section data on 1993-94 salaries of tenured faculty from nine state universities. They find that the coefficient on seniority is negative when not controlling for quality of research but is not different from zero when controlling for quality of research. I note that it makes sense to interpret their estimated coefficient as an overestimate of the true return to firm seniority. As argued analogously in Topel (1991), there is more mobility if the true coefficient is negative than when it is zero. If the true coefficient is negative then some otherwise undesirable offers are accepted. This increases the average wage of stayers and decreases the average wage of movers. So, OLS should overestimate the returns to seniority. That is, an estimate of zero returns is consistent with the true returns being negative.
} 
wage premium even when conditioning on productivity and that the negative wage premium holds equally across all university academic disciplines.

In contrast, my model predicts that a negative seniority wage premium in any perfectly competitive industry for which (i) human capital is general (or, at least industry- and not firm-specific) (ii) there are no trade secrets, (iii) outside offers are scarce, (iv) employees engage in multiple tasks of which some are visible and some are invisible to the outside market, and (v) employee output is costly to assess. The negative seniority wage premium exists even if one conditions on high productivity. Thus, for example, professional athletes who are free agents do not fall into the framework of this model as output is monitored constantly and any athlete who is paid below marginal product will be revealed as such.

My model can explain how the seniority wage premium may vary across disciplines, time, and schools. Exogenous factors, like the speed of information transmission and economic conditions, affect the probability that an individual will obtain an offer and so affect the relationship between wage and seniority. If the probability of an offer is one for a high-quality researcher, the negative seniority wage gap should disappear if one conditions on high-quality productivity. If the probability of an offer is zero, then wages are independent of seniority.

Though not modelled as such, my model can explain the existence of lowerquality academic journals. Though lower-quality journals may have less direct academic merit, their existence allows academic markets to behave efficiently.

The guaranteed base wage in the minimum bond efficient contract has an element of academic tenure in that tenure enables a university to guarantee a minimum wage ${ }^{17}$ for professors ${ }^{18}$. The most common criticism of academic tenure is that it encourages tenured professors to shirk. (See for example, Alchian, 1959.) The present model suggests that this argument is incomplete. The promise of firms to respond strategically to outside offers creates incentives for workers to invest

\footnotetext{
${ }^{17}$ The guaranteed base wage has bite especially in the case that the information about a worker is simultaneously revealed to both the inside and outside firms.

${ }^{18}$ Models of tenure include those of Chen and Ferris (1999), Carmichael (1988), Freeman (1977), and McPherson and Whinston (1983). See Siow (1998).
} 
efficiently. The model highlights the importance that a university's response to outside offers has in the promotion of efficient investment in research.

\section{A. Appendix}

Proposition A.1. $\kappa(\theta)$ increases in $\theta$ if $y_{t}$ increases in $\theta$ for $t \in[0,1]$. In addition, if both $y_{t}$ and $p_{t}$ increase in $\theta$ for $t \in[0,1]$ then $T(\theta)$ increases in $\theta$ and a low-ability worker is unable to produce $y(\kappa(h), h)$.

Proof. (1) If $\theta$ increases to $\theta^{\prime}$ then the assumption that $y_{t}$ increases in $\theta$ implies that the left hand side of equation $(2.1)$ is positive at $\left(\kappa(\theta), \theta^{\prime}\right)$. The assumption that $y$ is concave in $t$ then implies that $\kappa\left(\theta^{\prime}\right) \geq \kappa(\theta)$. (2) If $\theta$ increases to $\theta^{\prime}$ then the assumption that both $y_{t}$ and $p_{t}$ increase in $\theta$ imply that the left hand side of equation (2.2) is positive at $\left(T(\theta), \theta^{\prime}\right)$. The assumption that $y$ and $p$ are concave in $t$ then implies that $T\left(\theta^{\prime}\right) \geq T(\theta)$. Since $y$ is concave in $t$ and since $y_{t}$ increases in $\theta$, the results follows.

Proof. (PROPOSITION 2.2): Let

$$
\begin{gathered}
i^{\theta}(z)=\min \{t \in[0, \kappa(\theta)]: y(t, \theta) \geq z\}, \\
e^{\theta}(z)=\max \{t \in[\kappa(\theta), 1]: y(t, \theta) \geq z\} .
\end{gathered}
$$

If $y(\kappa(\theta), \theta)>z$ then I first show that $\arg \max _{t} G>\kappa(\theta)$ and then that $G$ is concave on $\left[\kappa(\theta), e^{\theta}(w)\right]$. Since $y_{t}>0$ on $[0, \kappa(\theta))$ with equality only at $t=\kappa(\theta)$, if $i^{\theta}(z)<t \leq \kappa(\theta)$ and $y(\kappa(\theta), \theta)>z$ then

$$
G_{t}(t, \theta, z)=p_{t}(t, \theta)[y(t, \theta)-z]+p(t, \theta) y_{t}(t, \theta)>0 .
$$

Thus, $G$ strictly increases in $t \geq i^{\theta}(z)$ until $t=\kappa(\theta)$ at which point $G_{t}>0$ so that $\arg \max G>\kappa(\theta)$. In addition, we note that if $y(t, \theta)=z$ at $t=e^{\theta}(w)$, this implies that $G_{t}<0$ at $t=e^{\theta}(w)$ since $y_{t}<0$ for $t>\kappa(\theta)$. If $y(t, \theta) \geq z$ then

$$
\begin{aligned}
G_{t t}(t, \theta, z)= & p_{t t}(t, \theta)[y(t, \theta)-z] \\
& +2 p_{t}(t, \theta) y_{t}(t, \theta)+p(t, \theta) y_{t t}(t, \theta) .
\end{aligned}
$$


Since $y$ is decreasing in $t$ for $t>\kappa(\theta), p$ is increasing in $t$, and $p$ and $y$ are concave in $t$, it is immediate that $G$ is concave in $t$ for $t \in\left[\kappa(\theta), e^{\theta}(w)\right]$.

Thus, $G$ is constant in $t$ and equal to $w$ for $t<i^{\theta}(w)$ (when $y(t, \theta)<w-$ $\exp \max \{0, x\}) ; G$ strictly increases in $t$ from $i^{\theta}(w)$ until $\kappa(\theta)$ (where $y(t, \theta)>$ $w-\exp \max \{0, x\}) ; G$ is concave in $t$ for $t \in\left[\kappa(\theta), e^{\theta}(w)\right]$ (where $y(t, \theta) \geq w-$ $\exp \max \{0, x\}$ ); $G$ is constant in $t$ and equal to $w$ for $t>e^{\theta}(w)$ (where $y(t, \theta)<w-$ $\exp \max \{0, x\}) ; G_{t}<0$ at $t=e^{\theta}(w)$ (if $y(t, \theta)=w-\exp \max \{0, x\}$ at $t=e^{\theta}(w)$ ). This implies that first order conditions are sufficient to characterize $\arg \max G$ in the case that $y(\kappa(\theta), \theta)>w-\exp \max \{0, x\}$. That is, either $G_{t}(t, \theta, w)=0$ at $t=\tau^{\theta}(w) \in\left[T(\theta), e^{\theta}(w)\right]$ or $G_{t}(1, \theta, w)>0$ at $t=\tau^{\theta}(w)=e^{\theta}(w)=1$.

If $y(T(\theta), \theta)<z$ then the worker is indifferent among all allocations.

Proof. (PROPOSITION 2.3): The result follows since the left-hand side of (2.3) decreases in $z$ and $t$ (as shown in the proof of Proposition 2.2).

Proof. (PROPOSITION 2.4): Let $y^{\theta}=y(\kappa(\theta), \theta)$ and let $p^{\theta}=p(\kappa(\theta), \theta)$ and recall that $z=w-\exp \max \{0, x\}$. I first construct the expected output of workers who receive the base wage. If $z<y^{\theta}$, then $\tau^{\theta}(z) \in(\kappa(\theta), 1]$ and any outside offer is revealed so that worker $\theta$ receives the base wage with probability $1-p\left(\tau^{\theta}(z), \theta\right)$. If $z=y^{\theta}$, then $\tau^{\theta}(z)=\kappa(\theta)$ and worker $\theta$ is indifferent between revealing an outside offer and not. That is, for every $\alpha^{\theta} \in[0,1]$, revealing an outside offer with probability $\alpha^{\theta}$ is optimal for worker $\theta$. Thus, if $z=y^{\theta}$, then the probability that worker $\theta$ receives the base wage is $1-\alpha^{\theta} p^{\theta}$. If $z>y^{\theta}$, then $\tau^{\theta}(w)=\kappa(\theta)$ and worker $\theta$ receives the base wage with probability one.

Let $S(z)$ represent the expected output of stayers who receive the base wage.

$$
S(z)=\left\{\begin{array}{ccc}
\frac{\pi^{l} y\left(\tau^{l}(z), l\right)\left[1-p\left(\tau^{l}(z), l\right)\right]+\pi^{h} y\left(\tau^{h}(z), h\right)\left[1-p\left(\tau^{h}(z), h\right)\right]}{\pi^{l}\left[1-p\left(\tau^{l}(z), l\right)\right]+\pi^{h}\left[1-p\left(\tau^{h}(z), h\right)\right]} & \text { if } & z<y^{l} \\
\frac{\pi^{l} y^{l}\left[1-\alpha^{l} p^{l}\right]+\pi^{h} y\left(\tau^{h}(z), h\right)\left[1-p\left(\tau^{h}(z), h\right)\right]}{\pi^{l}\left[1-\alpha^{l} p^{l}\right]+\pi^{h}\left[1-p\left(\tau^{h}(z), h\right)\right]} & \text { if } z=y^{l} \text { for } \alpha^{l} \in[0,1] \\
\frac{\pi^{l} y^{l}+\pi^{h} y\left(\tau^{h}(z), h\right)\left[1-p\left(\tau^{h}(z), h\right)\right]}{\pi^{l}+\pi^{h}\left[1-p\left(\tau^{h}(z), h\right)\right]} & \text { if } & y^{l}<z<y^{h} \\
\frac{\pi^{l} y^{l}+\pi^{h} y^{h}\left[1-\alpha^{h} p^{h}\right]}{\pi^{l}+\pi^{h}\left[1-\alpha^{h} p^{h}\right]} & \text { if } z=y^{h} \text { for } \alpha^{h} \in[0,1] \\
\pi^{l} y^{l}+\pi^{h} y^{h} & \text { if } & y^{h}<z
\end{array}\right.
$$

For $z<y^{l}$ an increase in $z$ decreases $\tau^{\theta}(z)$ (Proposition 2.3) and therefore increases $y\left(\tau^{\theta}(z), \theta\right)$ for $\theta \in\{l, h\}$. Although output increases for each type of 
worker as $z$ increases, $S(z)$ may decrease since the mix of workers who receive the base wage also fluctuates. For $y^{l}<z<y^{h}$ an increase in $z$ decreases $\tau^{h}(z)$ (Proposition 2.3) and therefore decreases $p\left(\tau^{h}(z), h\right)$, increases $y\left(\tau^{h}(z), h\right)$, and so $S(z)$ increases since the proportion of those who produce $y\left(\tau^{h}(z), h\right)$ and receive the base wage is increasing. For $z>y^{h}$ an increase in $z$ has no effect on $S(z)$. Note that $\lim _{z \uparrow y^{l}} S(z)>\lim _{z \downarrow y^{l}} S(z)$ since low-ability workers do not reveal outside offers when $z>y^{l}$. Thus as $z$ crosses $y^{l}$ there is an increase in the probability that a worker who receives the base wage has low ability. The effect is to decrease the expected output of those who receive the base wage. Analogously $\lim _{z \uparrow y^{h}} S(z)<\lim _{z \downarrow y^{h}} S(z)$ due to the increase in the probability that a worker who receives the base wage has high ability as $z$ crosses $y^{h}$. At $z=y^{l}, S(z)$ is a vertical line that connects the higher $\lim _{z \uparrow y^{l}} S(z)$ to the lower $\lim _{z \downarrow y^{l}} S(z)$. At $z=y^{h}, S(z)$ is a vertical line that connects the lower $\lim _{z \uparrow y^{h}} S(z)$ to the higher $\lim _{z \downarrow y^{h}} S(z)$. The upper hemi-continuous correspondence $S$ is a continuous function everywhere but at $z=y^{l}$ and $z=y^{h}$.

Since outputs lie between 0 and $y^{h}$, the range of $S(z) \subset\left[0, y^{h}\right]$. Since $S$ is convex-valued and closed on $\left[0, y^{h}\right]$ Kakutani's fixed point theorem guarantees that there exist $w \in\left[0, y^{h}\right]$ such that $S(w-E \max \{0, x\})=w$. Since the range of $S$ is $\left[0, y^{h}\right)$, the fixed points lie in $\left[0, y^{h}\right)$. The fact that $S$ is upper hemicontinuous on a closed and bounded interval ensures that the maximum of the set of fixed point exists. (Let $F(w)=S(w-\exp \max \{0, x\})-w$ on $I=\left[0, y^{h}\right]$. The set of fixed points is the set $\{w \in I: F(w)=0\}=F^{-1}(0)$ which is closed and bounded since $\{0\}$ is a closed set, $F$ is upper hemi-continuous, and $I$ is bounded. Since the set of fixed points is closed and bounded, its maximum exists.) The equilibrium spot market base wage is the maximum base wage for which $w^{s}=S\left(w^{s}-\exp \max \{0, x\}\right)$. Since $z^{s}=w^{s}-\exp \max \{0, x\}<y^{h}$, the highability worker invests $\tau^{h}\left(z^{s}\right)>\kappa(h)$ (Proposition 2.3) in the visible activity and so receives offers with positive probability.

Lastly, suppose the unique fixed point is $w$ such that $z=y^{l}$. A low-ability worker is indifferent between revealing an outside offer or not and so leaves with 
probability $\alpha^{l}$ upon receiving an offer. There exists $\alpha^{*} \in[0,1]$ such that the expected output of workers who receive the base wage equals the base wage only if $\alpha^{l}=\alpha^{*}$. If $z<y^{l}$ then the expected output is greater than the base wage and the base wage is bid up. If $z>y^{l}$ then the expected output is smaller than the base wage and the base wage is bid down. Thus, the equilibrium base wage must be $w_{s}=y^{l}+E \max \{0, x\}$. If $z=y^{l}$ and $\alpha^{l}>\alpha^{*}$ then the expected output is greater than the base wage and entry increases the probability of an offer at any given allocation of time and decreases the expected output. If $z=y^{l}$ and $\alpha^{l}<\alpha^{*}$ then the expected output is less than the base wage and exit decreases the probability of an offer at any given allocation of time and increases the expected output. Thus, $\alpha^{l}=\alpha^{*}$. Competition results in equality between the base wage and the expected output of workers who receive the base wage.

Note that since the output of the high-ability worker is greater than $w^{s}$, either $\tau^{h}\left(z^{s}\right)=1>T(h)$ or $\tau^{h}\left(z^{s}\right)$ satisfies equality 2.3 which implies that

$$
\begin{aligned}
& y_{t}\left(\tau^{h}\left(z^{s}\right), h\right)+p_{t}\left(\tau^{h}\left(z^{s}\right), h\right) \exp \max \{0, x\} \\
= & y_{t}\left(\tau^{h}\left(z^{s}\right), h\right)-p_{t}\left(\tau^{h}\left(z^{s}\right), h\right)\left(y\left(\tau^{h}\left(z^{s}\right), h\right)-w\right)-p\left(\tau^{h}\left(z^{s}\right), h\right) y_{t}\left(\tau^{h}\left(z^{s}\right), h\right) \\
= & y_{t}\left(\tau^{h}\left(z^{s}\right), h\right)\left(1-p\left(\tau^{h}\left(z^{s}\right), h\right)\right)-p_{t}\left(\tau^{h}\left(z^{s}\right), h\right)\left(y\left(\tau^{h}\left(z^{s}\right), h\right)-w\right)<0
\end{aligned}
$$

which implies that $\tau^{h}\left(z^{s}\right)>T(h)$ (since $y$ and $p$ are concave).

Proof. (THEOREM 2.5): Since the spot market base wage equals the expected output of those who receive it, the expected wage of those who stay is

$$
\frac{\pi^{h}(1-P(h)) y^{h}+\pi^{l}(1-P(l)) y^{l}}{\pi^{h}(1-P(h))+\pi^{l}(1-P(l))}
$$

where $y^{\theta}$ represents the spot market output of a worker of ability $\theta$ and $P(\theta)$ is the probability that a worker leaves conditional on ability $\theta \in\{l, h\}$. The expected wage of those who leave is

$$
\frac{\pi^{h} P(h) y^{h}+\pi^{l} P(l) y^{l}}{\pi^{h} P(h)+\pi^{l} P(l)}
$$


Since $y^{h}>y^{l}$, the theorem is proved if and only if

$$
\frac{\pi^{h} P(h)}{\pi^{h} P(h)+\pi^{l} P(l)}>\frac{\pi^{h}(1-P(h))}{\pi^{h}(1-P(h))+\pi^{l}(1-P(l))}
$$

which is true (after cross-multiplying and cancelling like terms) if and only if

$$
\frac{P(h)}{1-P(h)}>\frac{P(l)}{1-P(l)}
$$

which is true since

$$
P(h)>P(l)
$$

If addition, the average wage of high ability workers who leave is higher than that of high ability workers who stay since $y^{h}$ is greater than $w_{s}$.

Proof. (THEOREM 2.7): By Proposition 2.6, it suffices to minimize $B^{*}(w)$ over $w$ subject to the third and fourth individual rationality constraints where

$$
B^{*}(w)= \begin{cases}\pi^{l}\left(w-y^{l^{*}}\right)\left(1-p^{l^{*}}\right)+\pi^{h}\left(w-y^{h^{*}}+\widetilde{p}\left(y^{l^{*}}-w\right)\right) & \text { if } 0 \leq w \leq \bar{y} \\ \pi^{l}\left(w-y^{l^{*}}\right)\left(1-p^{l^{*}}\right)+\pi^{h}\left(w-y^{h^{*}}\right)\left(1-p^{h^{*}}\right) & \text { if } \bar{y} \leq w \leq y^{l^{*}} \\ \pi^{l}\left(w-y^{l^{*}}\right)+\pi^{h}\left(w-y^{h^{*}}\right)\left(1-p^{h^{*}}\right) & \text { if } y^{l^{*} \leq w \leq y^{h^{*}}} \\ \pi^{l}\left(w-y^{l^{*}}\right)+\pi^{h}\left(w-y^{h^{*}}\right) & \text { if } y^{h^{*}} \leq w\end{cases}
$$

is a continuous, piecewise linear function of $w$ that is negative for $0 \leq w \leq y^{l^{*}}$ (since $\left.w<y^{l^{*}}<y^{h^{*}}\right)$; positive for $y^{h^{*}} \leq w$; and increases in $w$ for $w \in\left(y^{l^{*}}, y^{h^{*}}\right)$ (since $\pi^{l}>0$ and $\left.\pi^{h}\left(1-p^{h^{*}}\right)>0\right)$. Thus, $B^{*}(w)$ has a unique root in $\left(y^{l^{*}}, y^{h^{*}}\right)$.

I now argue that the unique root of $B^{*}(w)$ is the base wage of the efficient contract that satisfies the fourth individual rationality constraint. If the bond is negative, the contract is profitable in the second period so that another firm can offer another contract that satisfies the first two individual rationality constraints and that offers a higher base wage that is also profitable and attracts workers away from the first contract at the end of the first period before the worker is revealed. Thus, the minimum bond consistent with the fourth individual rationality constraint must be greater than or equal to zero. If the bond is strictly positive then the contract loses money in the second period and there exists another contract 
with a bond that is smaller but still positive. Thus, the minimum bond consistent with rationality constraints 1,2 and 4 is one in which the base wage is $w_{e}$ such that $B^{*}\left(w_{e}\right)=0$, and the counteroffers are $C^{\theta}=C^{\theta^{*}}\left(w_{e}\right)$ for $\theta \in\{h, l\}$. Since the unique root of $B^{*}$ lies in $\left(y^{l^{*}}, y^{h^{*}}\right)$, the base wage $w_{e} \in\left(y^{l^{*}}, y^{h^{*}}\right)$ satisfies

$$
w_{e}=\frac{\pi^{l} y^{l^{*}}+\pi^{h} y^{h^{*}}\left[1-p^{h^{*}}\right]}{\pi^{l}+\pi^{h}\left[1-p^{h^{*}}\right]} \in\left(y^{l^{*}}, y^{h^{*}}\right) .
$$

It remains to show that the third individual rationality constraint is satisfied. That is, a firm would rather abide by the above efficient contract than renege. The firm is long-lived. There are short-lived workers who must choose an employer and make an investment decision in the first period of their life. If the firm reneges ${ }^{19}$, workers infer that the firm will honour only spot market contracts in the future and so workers make spot market investments if hired by a firm that reneges. In any case, the firm breaks even under the terms of the spot market contract so that the expected output $\left(\pi^{l} y\left(\tau^{l}\left(z_{s}\right), l\right)+\pi^{h} y\left(\tau^{h}\left(z_{s}\right), h\right)\right.$ as given in formula (2.5) is essentially transferred to the workers. However, the sum of the expected wage and non-wage benefits in the spot market is less than or equal to $\pi^{l}\left[y\left(\tau^{l}\left(z_{s}\right), l\right)+p\left(\tau^{l}\left(z_{s}\right), l\right) \exp \max \{0, x\}\right]+\pi^{h}\left[y\left(\tau^{h}\left(z_{s}\right), h\right)+p\left(\tau^{h}\left(z_{s}\right), h\right) \exp \max \{0, x\}\right]$

In the efficient contract a worker can expect to receive $\pi^{l}[y(T(l), l)+p(T(l), l) \exp \max \{0, x\}]+\pi^{h}[y(T(h), h)+p(T(h), h) \exp \max \{0, x\}]$ where $T(\theta)=\arg \max y(t, \theta)+p(t, \theta), \theta) \exp \max \{0, x\}$. Workers prefer the firms that offer the efficient contract to any firm that offers the spot market contract so that a firm prefers to honour the terms of the efficient contract.

Proof. (THEOREM 2.8): A worker who is revealed will leave the firm whenever $x>0$. Thus, the average wage of those who leave the inside firm equals

$$
\frac{\pi^{h} p^{h^{*}}(1-F(0)) y^{h^{*}}+\pi^{l} p^{l^{*}} w_{e}(1-F(0))}{\pi^{h} p^{h^{*}}(1-F(0))+\pi^{l} p^{l^{*}}(1-F(0))}=\frac{\pi^{h} p^{h^{*}} y^{h^{*}}+\frac{\pi^{l} p^{l^{*}}}{2} w_{e}}{\pi^{h} p^{h^{*}}+\pi^{l} p^{l^{*}}} .
$$

\footnotetext{
${ }^{19}$ The firm can renege in three ways: (1) not pay the base wage, (2) not meet the offer of the outside firm when output is revealed to be efficient, (3) meet the offer of the outside firm when output is revealed to be inefficient.
} 
and the average wage of those who remain with the inside firm equals

$$
\frac{\pi^{h} p^{h^{*}} y^{h^{*}} F(0)+\left(\pi^{h}\left[1-p^{h^{*}}\right]+\pi^{l}\left[1-p^{l^{*}}(1-F(0))\right]\right) w_{e}}{\pi^{h}\left[1-p^{h^{*}}(1-F(0))\right]+\pi^{l}\left[1-p^{l^{*}}(1-F(0))\right]} .
$$

The coefficient of $y^{h^{*}}$ in (A.2) is larger than that in (A.3) if and only if

$$
\pi^{h}\left[1-p^{h^{*}}(1-F(0))\right]+\pi^{l}\left[1-p^{l^{*}}(1-F(0))\right]>F(0)\left[\pi^{h} p^{h^{*}}+\pi^{l} p^{l^{*}}\right]
$$

which follows from

$$
\pi^{h}+\pi^{l}>\pi^{h} p^{h^{*}}+\pi^{l} p^{l^{*}}
$$

so the average wage of leavers is higher than that of stayers. Also, $y^{h^{*}}>w_{e}$ implies the result holds when conditioning on high ability.

\section{References}

[1] Acemoglu, D., and Pischke, J-S. (1998). Why Do Firms Train? Theory and Evidence. Quarterly Journal of Economics, 113 (1), Feb., 78-118.

[2] Alchian, A. A. (1959). Private Property and the Relative Cost of Tenure. In P. D. Bradley (Ed.), The Public Stake in Union Power. Charlottesville: University of Virginia Press.

[3] Altonji, J. G., and Shakotko, R. (1987). Do Wages Rise with Job Seniority? Review of Economic Studies, 54(3), July, 437-59.

[4] Bernhardt, D. (1995). Strategic Promotion and Compensation. Review of Economic Studies, 62(2), 315-339.

[5] Bernhardt, D., and Scoones, D. (1993). Promotion, Turnover, and Preemptive Wage Offers. American Economic Review, 83(4), 771-91.

[6] Bratsberg, B., Ragan, J.F. Jr., and Warren, J.T. (2003). Negative Returns to Seniority-New Evidence in Academic Markets. Industrial and Labor Relations Review, forthcoming.

[7] Carmichael, L. (1983). Firm Specific Human Capital and Promotion Ladders. Bell Journal of Economics, 14(1), Spring, 251-58.

[8] Carmichael, H. L. (1988). Incentives in Academics: Why Is There Tenure? Journal of Political Economy, 96(3), 453-72. 
[9] Chang, C., and Wang, Y. (1996). Human Capital Investment under Asymmetric Information: The Pigovian Conjecture Revisited. Journal of Labor Economics, 14 (3), 505-519.

[10] Chen, Z., and Ferris, J. S. (1999). A Theory of Tenure for the Teaching University. Australian Economic Papers, 38, 2-25.

[11] Dwatripont, Jewitt and Tirole (1999). The Economics of Career Concerns, Part I: Comparing Information Structures, Review of Economic Studies, 66, 193-198.

[12] Edlin, A.S., and Reichelstein, S. (1996). Holdups, Standard Breach Remedies, and Optimal Investment. American Economic Review, 86 (3), 478-501.

[13] Freeman, S. (1977). Wage Trends as performance Displays Productive Potential: A model and Applications to Academic Early Retirement. Bell Journal of Economics, 8, 419-43.

[14] Gibbons, R., and Katz, L. (1991). Layoffs and Lemons. Journal of Labor Economics, 9(4), October, 351-80.

[15] Hallock, K. F. (1995). Seniority and Monopsony in the Academic Labor Market: Comment. American Economic Review, 85(3), 654-657.

[16] Holmstrom, B. and Milgrom, P. (1991). Multitask Principal-Agent Analyses: Incentive Contracts, Asset Ownership, and Job Design. Journal of Law, Economics and Organization, 7(Spring), 24-52.

[17] Kahn, C., and Huberman, G. (1988). Two sided Uncertainty and "Up-orOut" Contracts. Journal of Labor Economics, 6(4), October, 423-44.

[18] Lazear, E.P. (1986a). Raids and Offer Matching. Research in Labor Economics; 8 (A), 141-165.

[19] Lazear, E.P. (1986b). Salaries and Piece Rates. The Journal of Business; 59 (3), 405-431.

[20] MacLeod,W.B., and Malcomson,J. M. (1988). Reputation and Hierarchy in Dynamic Models of Employment. Journal of Political Economy; 96(4), August, 832-54.

[21] Malcomson, J. M. (1984). Worker Incentives, Hierarchy and Internal Labour Markets. Journal of Political Economy; 92, 486-507.

[22] McPherson, M. S., and Whinston, G. C. (1983). The Economics of Academic Tenure: A Rational Perspective. A Journal of Economic Behavior and Organization, 4(2-3), 163-84. 
[23] Milgrom, P. R. (1988). Employment Contracts, Influence Activities, and Efficient Organization Design. Journal of Political Economy. 96(1), February, $42-60$.

[24] Milgrom, P. R. and D. J. Roberts (1988). An Economic Approach to Influence Activities in Organizational Design. American Journal of Sociology. 94, S154S179.

[25] Milgrom, P. R. and Oster, S. (1987). Job Discrimination, Market Forces, and the Invisibility Hypothesis. Quarterly Journal of Economics, 102, 453-476.

[26] Moore, W., Newman, R., and Turnbull, G. (1994). Seniority and Monopsony in the Academic Labor Market: The Case of Economists, manuscript, Louisiana State University.

[27] Moore, W., Newman, R., and Turnbull, G. (1998). Do Academic Salaries Decline with Seniority? Journal of Labor Economics. 16(2), April, 352-66.

[28] Ransom, M. R. (1993). Seniority and Monopsony in the Academic Labor Market. American Economic Review, 83(1), 221-33.

[29] Ricart i Costa, J. E. (1988). Managerial Task Assignment and Promotion, Econometrica, 56, March, 449-166.

[30] Siow, A. (1998). Tenure and other Unusual Personnel Practices in Academia. Journal of Law Economics and Organization, 14(1), 152-73.

[31] Topel, R. H. (1991). Specific Capital, Mobility, and Wages: Wages Rise with Job Seniority. Journal of Political Economy, 99(1), February, 145-76.

[32] Waldman, M. (1984). Job Assignments, Signalling, and Efficiency. Rand Journal of Economics, 15(2), 255-267.

[33] Waldman, M. (1990). Up or Out Contracts: A Signalling Perspective. Journal of Labor Economics, 8(2), 230-250. 